\title{
Verification of the eccentrically compressed reinforced concrete column calculation model based on the results of a full-scale experimental study
}

\author{
Mikhail Andreev *, Sergey Bulushev and Marina Dudareva \\ Moscow State University of Civil Engineering, Yaroslavskoe shosse, 26, Moscow, 129337, Russia
}

\begin{abstract}
The article presents the results of a numerical experiment consisting in a test of an eccentrically compressed reinforced concrete column and comparison of the results obtained with the results of experimental studies. With the development of numerical methods and software packages, methods (techniques) of modeling structural elements using more detailed calculation models with solid finite elements that allow direct consideration of the joint behavior of concrete and reinforcing bars become relevant. The use of such methods requires verification of individual load-bearing structural elements, such as columns, beams, slabs. The article refers to a nonlinear concrete model - Continuous Surface Cap Model (CSCM). This model is implemented in the LS-DYNA software package and enables to consider the joint behavior of reinforcing bars and concrete, using bar (for reinforcing bars) and solid (for concrete) finite elements. An eccentrically compressed reinforced concrete column of square section with dimensions of $150 \times 150 \times 1150(\mathrm{~h}) \mathrm{mm}$ is chosen as an object of modeling. The studies have shown that the ultimate breaking load on the column based on the results of numerical modeling is consistent with the experimental values (discrepancy does not exceed 3.4\%). The pattern of development of cracks and fractures, obtained from the results of modeling in the LS-DYNA software package corresponds to the pattern of fractures obtained as a result of experimental studies. According to comparison of the results obtained, it can be argued that a numerical test showed good agreement with the results obtained during full-scale experiments.
\end{abstract}

\section{Introduction}

As already mentioned earlier in [1], simplified bar and shell finite elements are generally used in the Russian Federation for simulation of loading diagrams of buildings and structures. This approach is quite acceptable for calculation of static loads. The safe shutdown earthquake (SSE) calculation requires using more detailed calculation models

*Corresponding author: misha-andreev_93@mail.ru 
with solid finite elements, enabling to consider directly the joint behavior of concrete and reinforcing bars.

This requires an adequate choice of load-strain diagrams or models of materials. In such software packages as ANSYS, LS-DYNA, etc., it is possible to use the diagrams shown in [2] and model the joint behavior of concrete and reinforcing bars with the help of bar (for reinforcement bars) and solid (for concrete) finite elements. In [1], a reinforced concrete beam was studied, simulated considering the joint behavior of concrete and reinforcing bars. Further, let us consider the study of the reinforced concrete column.

\section{Problem statement}

Numerical studies were carried out in the LS-DYNA finite-element software package in which nonlinear, static, and dynamic methods were implemented. It implements a nonlinear concrete model - Continuous Surface Cap Model (CSCM) that enables to consider the direct reinforcement of concrete with bars using solid (for concrete) and bar (for reinforcing bars) finite elements [3].

The aim of the study is verification of a numerical model of an eccentrically compressed reinforced concrete column based on the results of a full-scale experiment.

An eccentrically compressed reinforced concrete column of square section with dimensions of 150x150 mm, experimentally studied in [4], is chosen as an object of numerical modeling. Column height is $1150 \mathrm{~mm}$. Compressive load eccentricity is $15 \mathrm{~mm}$. Diameter of longitudinal reinforcing bars is $12 \mathrm{~mm}$, diameter of transverse reinforcing bars is $6 \mathrm{~mm}$. For smooth load transfer, the ends the column were reinforced with a steel plate 5 $\mathrm{mm}$ thick, $80 \mathrm{~mm}$ high.

In the numerical modeling of a column, the following parameters were assigned in the software package. Material of reinforcing bars is steel; in the reinforcing bars simulation, an ideally elastic-plastic Prandtl model was used with the initial modulus of elasticity $\mathrm{E}=$ $2.1 \cdot 10^{\wedge} 5 \mathrm{MPa}$. The yield strengths were assumed equal to $\sigma_{\mathrm{T}}=561 \mathrm{MPa}$ for longitudinal and $\sigma_{\mathrm{T}}=314 \mathrm{MPa}$ for transverse bars, and the limiting plastic deformations $\varepsilon_{\text {plastic }}=0.1$. The steel density $\rho=7.850 \mathrm{~kg} / \mathrm{m} 3$.

For concrete, a CSCM nonlinear material model is used, the mean cylindrical compressive strength is $f_{\mathrm{cm}}=30 \mathrm{MPa}[5,6]$. The density of concrete $\rho=2.400 \mathrm{~kg} / \mathrm{m} 3$. Fig. 1.

The design scheme, geometrical dimensions, and the reinforcement pattern are shown in

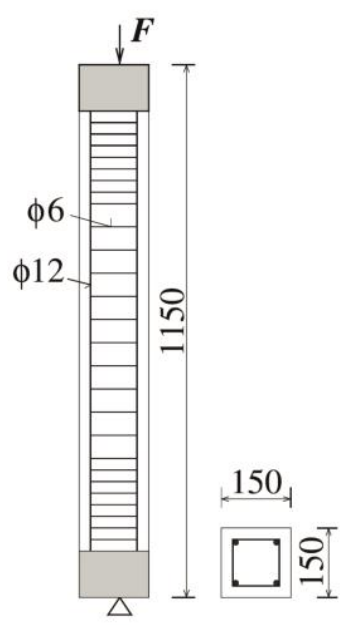

Fig. 1. Reinforced concrete column structure. 
Let us consider the results of the column experimental tests carried out in [4].

Figure 2 shows the fracture pattern obtained in the experimental study.

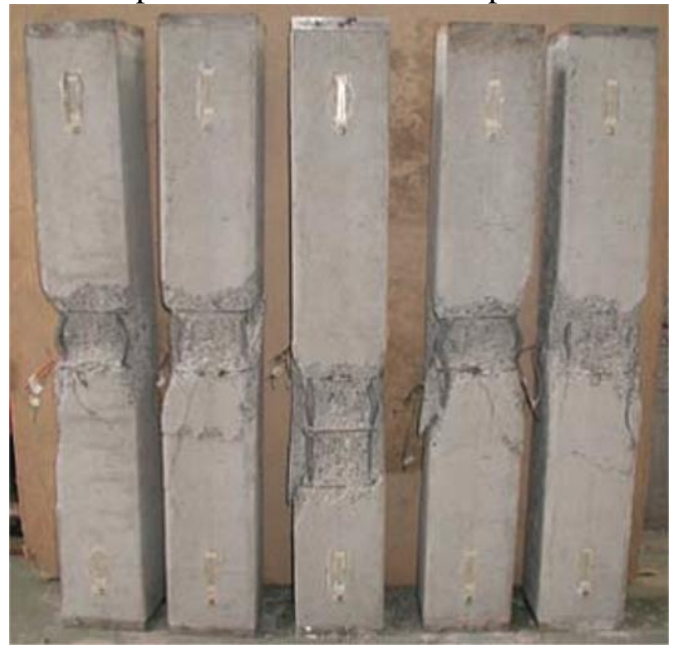

Fig.2. Fracture of columns in the test.

The mean ultimate load at which the test specimens are fractured $\mathrm{P}_{\mathrm{u}}=607.8 \mathrm{kN}$.

The calculation model of the reinforced concrete column, the FE mesh, and the reinforcement cage are shown in Fig. 3 a, b, c.

a)

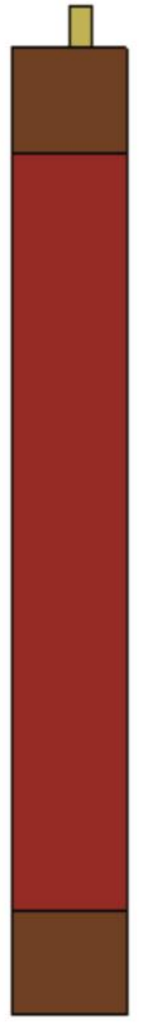

b)

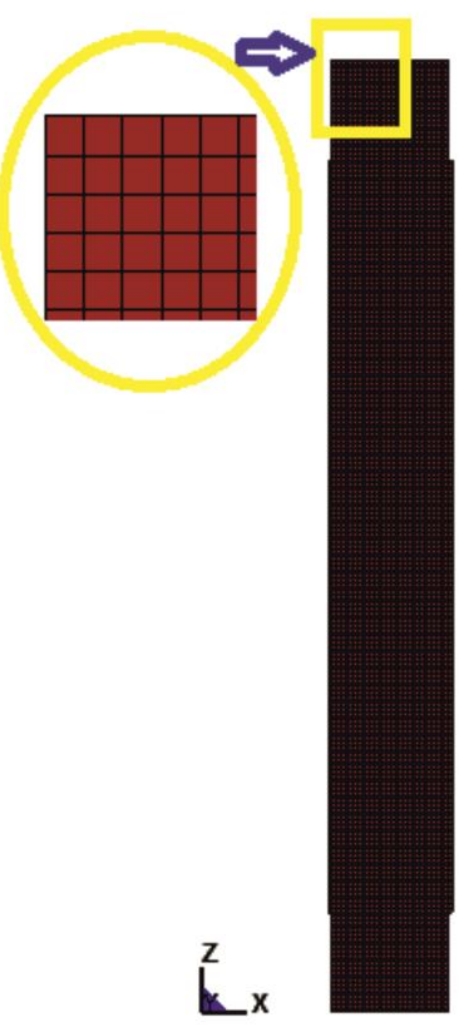

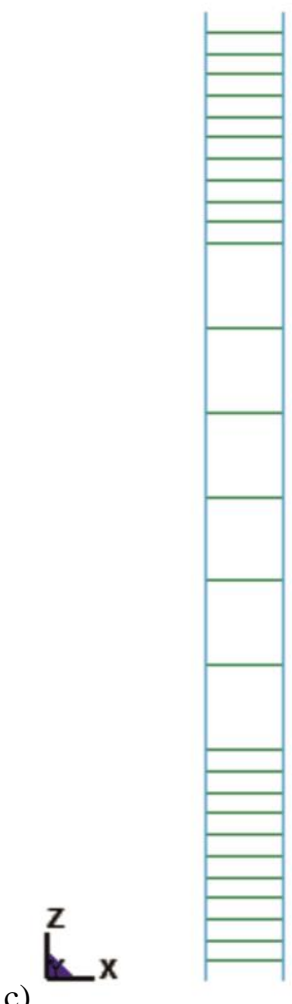

c)

Fig. 3. Calculation model of the reinforced concrete column (a), FE mesh (b), reinforcement cage (c). 
The model was divided into finite elements (FE) of two types: longitudinal and transverse reinforcing bars were broken into bar FE; concrete and steel plate were broken into solid FE in the form of a parallelepiped. Longitudinal reinforcing bars were divided into 256 rod FE each, transverse reinforcing bars were divided into 36 rod FE each. Concrete was divided into 200,000 solid FEs. The coupling between the FEs of concrete and reinforcing bars was implemented using the Euler-Lagrangian coupling algorithm.

\section{Calculation results}

The calculation results show that the fracture pattern of the column in a numerical experiment corresponds to the fracture pattern in full-scale tests.

Figures 4-6 show comparative patterns of fracture based on the results of full-scale tests and the results of calculations in the LS-DYNA software package.
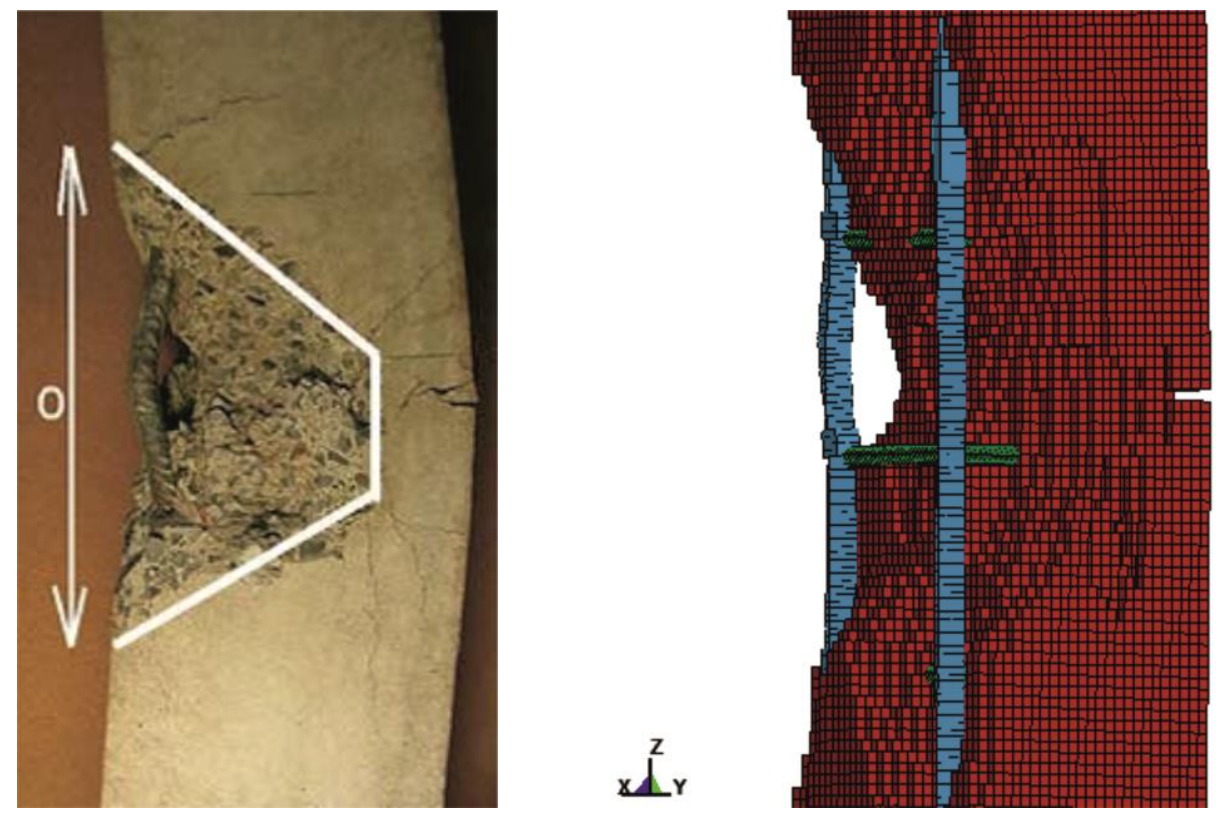

Fig. 4. Fracture pattern of the reinforced concrete column (side view). Experiment results (left), numerical study results (right). 

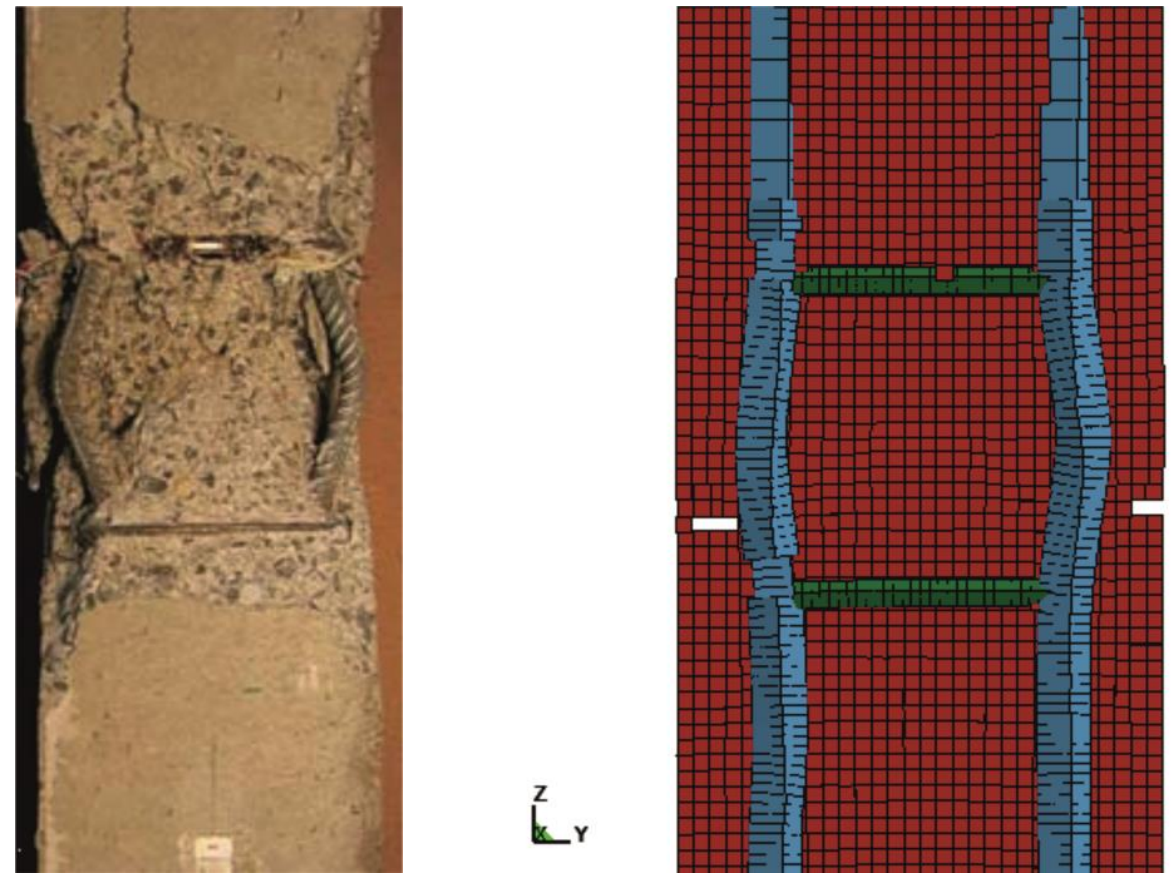

Fig. 5. Fracture pattern of the reinforced concrete column (front view). Experiment results (left), numerical study results (right).

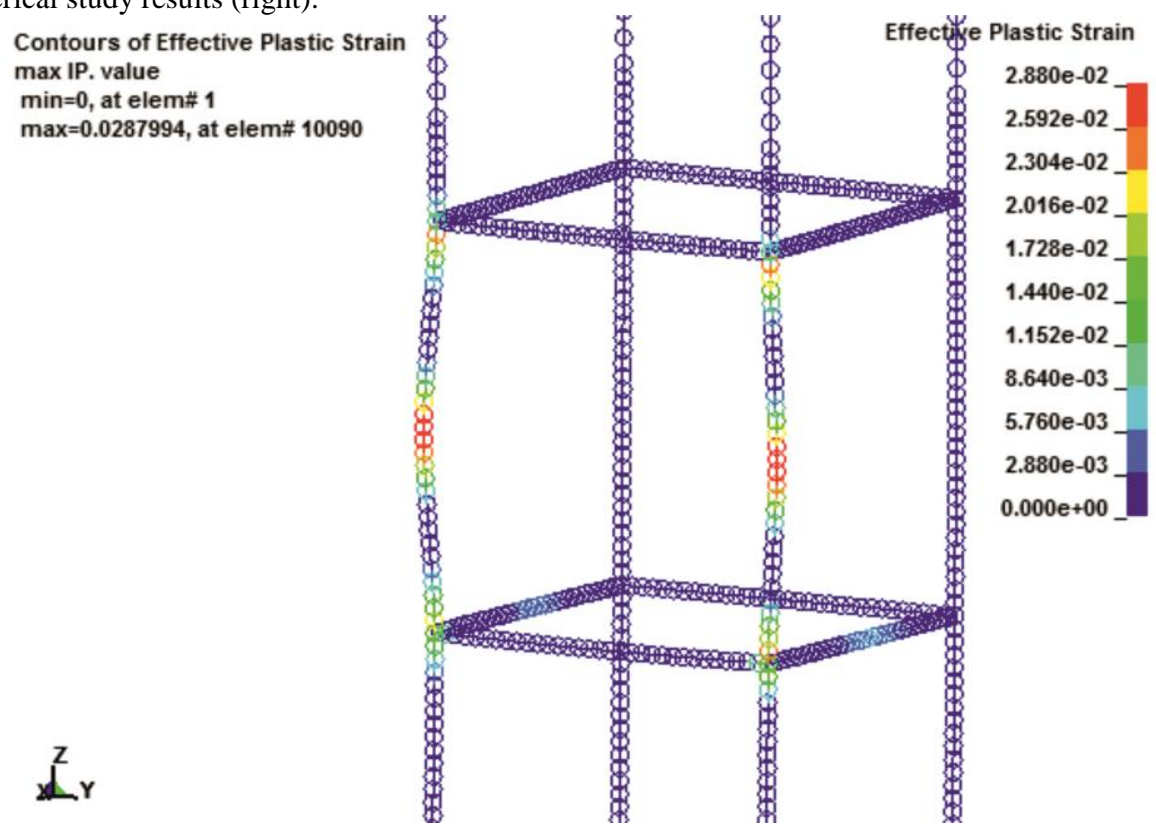

Fig. 6. The intensity of ultimate plastic deformations $\varepsilon_{\text {plastic }}$ in the reinforcement cage with the deformation pattern of reinforcing bars.

The ultimate load at which the beam fractures according to the modeling results $\mathrm{P}_{\mathrm{u}}=$ $587.5 \mathrm{kN}$. 


\section{Conclusions}

1. The ultimate (breaking) load on the reinforced concrete column based on the modeling results in the LS-DYNA software package is quite similar to the results of the experimental study (3.4\% discrepancy).

2. The pattern of development of cracks and fractures, obtained from the results of modeling in the LS-DYNA software package corresponds to the pattern of fractures obtained as a result of experimental studies.

3. According to analysis of the results obtained, it can be argued that a numerical test showed good agreement with the results obtained during full-scale experiments.

Based on the results of this work, we have seen that the LS-DYNA software package will enable to perform correctly solid simulation of compressed-bent reinforced concrete elements with the definition of non-linear load-strain diagrams of materials. The method of direct reinforcement of concrete with reinforcing bars used in the work can be applied in carrying out scientific research and analysis of load-bearing structures of reinforced concrete buildings and structures. The numerical study of behaviour of reinforced concrete slabs using the method of direct concrete reinforcement with reinforcing bars is still relevant today.

This study was performed with the financial support of the RF Ministry of Education and Science, grant \#7.1524.2017/Project Part.

\section{References}

1. Mkrtychev, O.V. Verification of the reinforced concrete beam model based on the results of a full-scale experimental study / O.V. Mkrtychev, M.I. Andreev // MATEC Web of Conferences. - 2018. - 196, 01029.

2. SP 63.13330.2012 Concrete and Reinforced Concrete Structures. Summary (2012)

3. Mkrtychev, O.V. Verification of the spar model of a reinforced concrete beam / O.V. Mkrtychev, M.S. Busalova, V.B. Dorozhinskiy // MATEC Web of Conferences. - 2017. 117, 00124.

4. J. Němeček. Effect of Stirrups on Behavior of Normal and High Strength Concrete Columns / P. Padevět, Z. Bittnar // Acta Polytechnica - 2004. - 44, No.5-6

5. Mkrtychev, O.V. Comparative analysis of results from experimental and numerical studies on concrete strength / O.V. Mkrtychev, D.S. Sidorov, S.V. Bulushev // MATEC Web of Conferences. - 2017. - 117, 00123.

6. T. Telford Designers' guides to the Eurocodes. Designers' guides to Eurocode 2 : Design of concrete structures designers' guide to EN1992-1-1 and EN1992-1-2 Eurocode 2 : Design of concrete structures general rules and rules for buildings and structural fire design (2005) 